\title{
Old age psychiatry: a speciality in transition
}

\section{Results of the 1996 survey}

\author{
John Wattis, Andrew MacDonald and Paul Newton
}

\begin{abstract}
Aims and methods We aimed to update information on the development of old age psychiatric services using a postal survey of consultants.

Results The response rate (51\%) was lower than previous surveys in the 1980s. Senior academic appointments showed little increase and academic posts were largely National Health Service (NHS) funded. Services had smaller catchment areas and increased numbers of staff in medicine, nursing and social work, but not in occupational therapy, physiotherapy and psychology. Relative workload was increasing and most services included early-onset dementia. There was a decrease in provision of NHS long-stay beds with only marginal changes in other facilities.

Clinical implications Services were offering more to patients than previously. Weakness in academic development may cause problems for the future; the results suggested that recruitment in some disciplines may already be problematical. There is a need to develop the role of NHS long-stay facilities.
\end{abstract}

Earlier reports on old age psychiatry services demonstrated a steady improvement in consultant numbers and facilities (Wattis et al, 1981; Wattis \& Arie, 1984; Wattis, 1988). The last survey was conducted over 10 years ago and Department of Health (Wattis, 1991; Allen, 1994) and Royal College of Psychiatrists (1996) data do not give sufficient reliable information to follow developments. A further survey was therefore undertaken to determine how the speciality had fared during the preceding 10 years.

\section{The study}

A modified version of earlier questionnaires included new topics such as details of services for people with pre-senile dementia. Four hundred and seventy consultants on the Faculty for Psychiatry of Old Age list were sent questionnaires. A second questionnaire was sent to each non-responder.

\section{Findings}

Of 470 questionnaires, 242 (51\%) were returned. Eleven respondents without a formal sessional commitment to older adults were excluded. Numbers responding to individual questions varied so results are given as percentages or fractions.

\section{Characteristics of consultants}

Posts held by academic psychiatrists in 1995 were (1985 survey figures in parentheses): professor, five (four); reader, one; senior lecturer. seven (eight); lecturer, three; and other, five.

Fourteen academic posts were said to be funded by the National Health Service (NHS), four by the university, one by both and in two cases funding was 'other' or unspecified. The mean number of university sessions was four and the mean number of NHS sessions eight (some describing themselves as working more than 11 sessions in all). Sixty-five consultants had honorary university titles.

The mean number of NHS sessions worked was 10.2 (range 3-15) with the mean number in old age 9.5 (1-15). Only $16 \%$ worked sessions in general psychiatry (mean 3.9, range 1-9) and only $4 \%$ in private old age psychiatry (mean 1.8 sessions, range 1-8).

Nearly three-quarters of respondents had been appointed to their present posts and nearly twothirds had first been appointed to their first consultant post since the last survey. Fifty-six reported this was not their first consultant post (see Fig. 1). The majority had held only one previous post, but seven had held two and one consultant had held three.

\section{Personal training}

Over three-quarters of respondents had senior registrar training (mean length 38 months, including 20 months in old age psychiatry). Seventy-six per cent had trained full-time, $12 \%$ part-time and $12 \%$ in a mixture of full-time and part-time posts. Sixteen per cent had trained in university (lecturer) posts. 


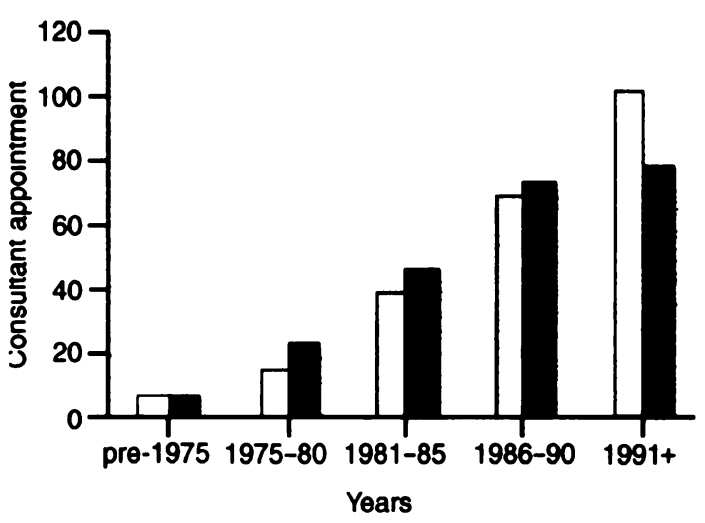

Fig. 1. Consultant appointments (five-year periods, $n=231$ ): $\square$, present post; $\square$, first consultant.

\section{Work patterns}

Three-quarters of respondents worked in a group of two or more. In just over a fifth of cases. general psychiatrists provided some services to old people. restricted to functional illness in three-quarters. Nearly $90 \%$ of respondents provided some services for patients with early-onset dementia and nearly two-thirds included them in the core description of their services, although only $10 \%$ had any dedicated staffing or facilities. Nearly two-thirds took over psychiatric responsibility for patients growing old in the community but only just over a third for those growing old in hospital. Age cut-offs for organic disorders were usually 65 years (range 45-70 years). Over twothirds of services had no cut-off for dementia. For functional disorder virtually all services had an age cut-off, mainly at 65 years (range 60-75 years).

\section{Staffing}

Table 1 gives the whole time equivalent number of staff in each grade together with the rate per thousand population where appropriate. Figures from the 1985-86 survey are given for comparison. Four-fifths of respondents worked with community mental health teams (CMHTs). In $38 \%$ they were recognised as team leader. A further $45 \%$ were informal leaders, $15 \%$ had no leadership role and $2 \%$ dealt with the team 'by referral only'. Seventy-eight per cent said team members accepted direct referrals from general practitioners (GPs) but in only a fifth of cases did consultants accept 'medical responsibility' for such referrals and only a tenth reported problems of priority conflict between GP and internal team referrals. Over $95 \%$ reported good relationships between the CMHT and the rest of the service.

Table 1. Staffing levels

\begin{tabular}{|c|c|c|}
\hline Type of stail & $\begin{array}{l}\text { Whole time equivalent } \\
\text { (1985-86 survey) }\end{array}$ & $\begin{array}{l}\text { Whole time equivalent/ } \\
1000 \text { elderly } \\
\text { served(1985-86 survey) }\end{array}$ \\
\hline $\begin{array}{l}\text { Medical/clinical assistant } \\
\text { Staff grade } \\
\text { Associate specialist } \\
\text { Senior clinical medical officer } \\
\text { Clinical medical officer } \\
\text { Senior registrar/specialist registrar } \\
\text { Registrar/senior house officer } \\
\text { General practitioner trainee/senior house officer } \\
\text { Other medical } \\
\text { Social worker } \\
\text { Social welfare officer } \\
\text { Other social worker } \\
\text { Psychologist } \\
\text { Psychology technician } \\
\text { Occupational therapist } \\
\text { Occupational therapist 'helper' } \\
\text { Physiotherapist } \\
\text { Physiotherapy 'helper' } \\
\text { Community psychiatric nurse } \\
\text { Other }\end{array}$ & $\begin{array}{l}199(115) \\
67^{\prime} \\
34(26) \\
10^{\prime} \\
31^{\prime} \\
125(40) \\
216(179) \\
39(41) \\
9^{\prime} \\
226(203) \\
3(39) \\
49^{\prime} \\
83(99.8) \\
39^{\prime} \\
217(239) \\
115(284) \\
50(111) \\
22(55) \\
647(563) \\
70^{\prime}\end{array}$ & $\begin{array}{l}0.048(0.033) \\
0.055 \\
0.035(0.026) \\
0.039 \\
0.034 \\
0.073(0.041) \\
0.058(0.042) \\
0.043(0.036) \\
0.043 \\
0.081(0.046) \\
0.026(0.036) \\
0.045 \\
0.033(0.035) \\
0.043 \\
0.066(0.058) \\
0.053(0.079) \\
0.032(0.034) \\
0.037(0.041) \\
0.192(0.117) \\
0.088\end{array}$ \\
\hline
\end{tabular}

1. These grades were not reported in an earlier survey. 


\section{Workload and facilities}

The average respondent had a catchment area of 22000 old people with 372 (including 263 new) referrals per annum. About $49 \%$ were assessed at home by the consultant, $10 \%$ by senior registrars or other doctors and $11 \%$ by other team members. In only $4 \%$ of referrals were patients seen at home by a team (except for training purposes). Ten per cent were initially seen as out-patients, $13 \%$ as ward-liaison referrals and $3 \%$ were directly admitted.

The average service had 21 acute beds (0.95/ 1000 elderly); about $45 \%$ were located on a general hospital site, $40 \%$ on a mental hospital site and $15 \%$ elsewhere, the majority in or adjacent to the catchment area. Nearly threequarters of services had separate wards for functional and organic disorders and the average length of stay was 38 days. Slightly more than half of the beds were used for organic disorder, the rest for functional disorders.

Fifty-six respondents had no long-stay beds. The mean level of long-stay provision was 24 beds (1.1/1000 elderly). Sixteen per cent of longstay beds were on a general hospital site, $44 \%$ on a mental hospital site and $40 \%$ elsewhere, mostly within the catchment area. About a quarter of services had separate long-stay facilities for functional mental illness. The average service provided 5.2 respite beds, mostly on long-stay wards. About $11 \%$ of NHS purchased provision was in the private sector and $4 \%$ in the charitable sector.

Only $11(5 \%)$ services had a joint ward in old age medicine/psychiatry. The mean number of beds in such wards was 11 (range 2-22). The mean number of day hospital places for functional patients was 23 (1/1000 elderly), available on average three days (range 1-7) per week. For organic disorders the mean number was 26 (1.2/1000 elderly) available on average four days (range 1-7) per week.

Involvement in audit, education and research Eighty-nine per cent of respondents were involved in clinical audit, just over half in some form of research, $69 \%$ in undergraduate teaching, $92 \%$ in postgraduate medical teaching. $51 \%$ in nurse teaching and $60 \%$ in teaching other groups.

\section{Comment}

On the basis of data kept by the Faculty of Psychiatry of Old Age (S. Benbow, personal communication, 1998) we estimate there are probably more than 420 consultants in the field at present. Our $51 \%$ response rate means that conclusions and comparisons must be tentative. Although it is possible that the more hard pressed consultants may have been less likely to respond, resulting in the survey painting a rather optimistic picture of staffing and facilities. we have no reason to suspect systematic bias. The variation of provision revealed in this survey and the variation in investment revealed by a recent Alzheimer's Disease Society survey (Alzheimer's Disease Society, 1997) seems indefensible in the light of guidance on services over many years (Department of Health and Social Security, 1972; National Health Service Health Advisory Service, 1982; Royal College of Physicians of London \& The Royal College of Psychiatrists, 1989). NHS 'market' reforms may have impeded geographical equity rather than encouraging it. A return to some national guidance is necessary and national service frameworks may help.

The increased overall number of academic posts was not reflected in senior posts and, sadly, a number of major university medical schools were still without a professor in the speciality. The majority of academic posts were funded as NHS initiatives suggesting lack of commitment from medical schools. This is of special concern for the education of future general practitioners considering the prevalence of mental illness in old age and its poor detection and management (Macdonald, 1986: O'Connor et al, 1988; Iliffe et al, 1991; Wind et al, 1994). Developing research programmes in old age psychiatry is also almost impossible without strong university departments. A central initiative to develop investment in academic old age psychiatry, preferably on a multi-disciplinary basis, is long overdue.

The increased sessional commitment of consultants, first noted in 1983, continued with most now working full-time in the speciality. In 1980 three-quarters of consultants worked alone, by 1996 only a quarter did so. Nevertheless, there is independent evidence of consultants working excessive hours (Benbow et al, 1993) and a worrying trend for there to be proportionately more posts filled by movement than by new appointment. A marked increase in whole time equivalent senior (specialist) registrars from 28 in 1983, through 40 in 1985-86 to 120 at the present may help solve this problem.

Increased involvement with early-onset dementia, often without dedicated resources and the presence in the community of increasing numbers of people growing old with mental illness were potential sources of increased workload. In $83 \%$ of services, consultants had a formal or informal leadership role, but a substantial minority had none and this is a potential area for further qualitative research.

Non-consultant medical staffing had increased. particularly in the non-training grades. Further research is needed into the effects of this. 
Numbers of CMHT staff were probably underestimated in comparison to the 1985-86 survey. Despite this, whole time equivalent numbers of staff in some disciplines showed an increase. This was most marked with community psychiatric nurses (CPNs) and qualified social work staff. Unfortunately, other professions such as occupational therapy, physiotherapists and psychologists showed an apparent decline in numbers.

The rates of provision per thousand elderly served tended to support this conclusion. They showed an apparent $50 \%$ increase in medical/ clinical assistant sessions, a greater than $50 \%$ increase in senior registrar/specialist registrar sessions and smaller increases in senior house officers and associate specialists. In the nonmedical grades, qualified social workers had increased by nearly $100 \%$ but social welfare officers had all but disappeared to be replaced by other social work staff. The rate for psychologists was reduced, partly mitigated by the emergence of the psychology technician posts. There was a marginal increase in the rates for occupational therapists but a reduction in unqualified helpers. In physiotherapy the trends were in the opposite direction. The rate of provision of CPNs was increased.

Many of these increases probably related to reduced catchment areas with stable staffing. The increase in CPN provision may also have reflected a shift from hospital to community. The reduced rate of provision from qualified psychologists could reflect psychologists migrating out of old age to 'income generate' elsewhere or working outside multi-disciplinary teams.

Catchment area size at $\mathbf{2 2} 000$ old people still fell well short of College guidelines of one consultant 10000 elderly (Royal College of Psychiatrists, 1992). Overall rates and new referral rates were both up by about $20 \%$ since 1986. presumably reflecting an interaction of increased demand for and avallability of services. The bias to community assessment, the reluctance to admit patients directly without preassessment and the relatively small use of outpatient departments, shown previously, were maintained. An important component of liaison psychiatry assessments in non-psychiatric hospital beds was also seen.

Acute bed rates had not changed significantly but average length of stay had reduced from 43 to 38 days since 1986 . There was a marginal increase in the proportion of acute beds on general hospital sites. The rate of provision of NHS long-stay beds had fallen by two-thirds. This, confirmed by earlier work from Alzheimer's Disease Society (1993), probably represented a net loss of NHS provision to means-tested private nursing home care. Around a tenth of remaining NHS beds were purchased through the private sector. Some serious scandals have occurred
(Health Service Commissioner, 1996) following patients being moved against consultant advice. Given that the majority of residential care for old people with dementia and other mental illness is likely to remain outside the NHS, specific training for dementia care in these settings must be a priority and may be one role for a reduced NHS provision.

There was no expansion in acute beds. Any change in day hospital provision was probably marginal.

Joint units with physicians in geriatric medicine were not thriving. Nineteen such units were identified in 1981 but only 11 in the present survey. On the other hand, involvement in liaison old age psychiatry continued (although not necessarily as well developed as general psychiatry liaison). Research is needed to establish the best methods of joint working.

The pleasing involvement of respondents in clinical audit, research, teaching and training was offset by the reduction in the proportion of respondents involved in training nurses which had fallen from about $70 \%$ in $1985-86$ to just over $50 \%$.

\section{References}

ALLEN, P. (1994) Medical and dental staffing prospects in the NHS in England and Wales 1992. Health Trends, 25. 118-125.

ALZHEIMER'S DISEASE SOCIETY (1993) NHS Psychogerlatrlc Continuing Care Beds: A Report. London: Alzheimer's Disease Society.

- (1997) No Accounting for Health: Health Commissioning for Dementia, pp. 1-26. London: Alzheimer's Disease Society.

BENBOW, S. M., JOLLEY, D. \& LEONARD, I. J. (1993) All work? $A$ day in the life of geriatric psychiatrists. International Journal of Geriatric Psychiatry. 8, 1019-1022.

DEPARTMENT OF HEALTH AND SOCIAL SECURTY (1972) Setvices For Mental Illness Related to Old Age, HM(72)71. London: DHSS.

Health SeRvice Commissioner (1996) Report of the Health Service Commissioner on Selected Investigations October 1995-March 1996. pp. 116-117. London: HMSO.

ILfFE., S., Haines, A., GaluJvans, S., et al (1991) Assessment of elderly people in general practice. 1. Social circumstances and mental state. British Journal of General Practice, 41, 9-12.

MACDONALD, A. (1986) Do general practitioners 'miss' depression in elderly patients? British Medical Journal, 292. 1365-1367.

National Health Service Health Advisory Service (1982) The Rising Tide: Developing Services for Mental Illness in Old Age. Sutton: NHS Health Advisory Service.

O'CONNOR, D. W.. POLITT, P. A.. HYDE, J. B., et al (1988) Do general practitioners miss dementia in elderly patients? British Medical Journal, 297. 1107-1110.

ROYAL COLLEGE OF PSYCHIATRISTS (1992) Mental Health of the Nation. The Contribution of Psychiatry. A Report of the President's Working Group Councll Report CR16. London: Royal College of Psychiatrists.

- (1996) Annual Census of Psychiatric Staffing. Occasional Paper OP38. London: Royal College of Psychiatrists. 
Royal College of Physicians of london \& Royal College OF PSYCHIATRISTS (1989) Care of Elderly People with Mental Illness: Specialist Services and Medical Training. London: Royal College of Physicians and Royal College of Psychiatrists.

Wartis, J. P. (1988) Geographical variations in the provision of psychiatric services for old people. Age and Ageing, 17, 171-180.

- (1991) To the editor. Health Trends, 23, 44.

-. WATtis, L. \& ARIE, T. H. (1981) Psychogeriatrics: a national survey of a new branch of psychiatry. British Medical Journal, 282, 1529-1533.

- \& ARIE, T. H. (1984) Further developments in psychogeriatrics in Britain. British Medical Journal, 289. 778.
Wind, A. W., Van Staveren, G., Schellevis, F. G., et al (1994) The validity of the judgement of general practitioners on dementia. International Joumal of Geriatric Psychiatry, 9. 543-549.

John Wattis, Medical Director, Leeds Community and Mental Health Services NHS Trust, The Mansion, Meanwood Park Hospital, Tongue Lane, Leeds LS6 4QB; Andrew MacDonald, Consultant Psychiatrist, Wakefield and Pontefract Community Health Trust; and Paul Newton, Clinical Audit Manger, Leeds Community and Mental Health Services NHS Trust, Leeds

\title{
National differences in disulfiram prescribing
}

\author{
Jonathan Chick and Colin Brewer
}

\begin{abstract}
Aims and method To test the impression of wide national differences in the use of deterrent medication in the treatment of alcohol dependence, data showing comparative sales of disulfiram in 13 countries were obtained.

Results Sales in Britain were lowest, and less than a tenth of those in Denmark. Rates bore no relation to alcohol sales or an index of alcohol-related problems in the 13 countries.

Clinical implications British doctors may apply a particularly cautious risk/benefit ratio for disulfiram. The disparity may also reflect the predominantly nonmedical approach to treating alcohol dependence in Britain.
\end{abstract}

Hughes \& Cook (1997) reported that, in a trial of acamprosate, patients who chose to take disulfiram in addition to their trial drug had the lowest relapse rate (Bresson et al, 1998). In a pilot study research showing that naltrexone and acamprosate have clinically significant effects in reducing relapse in alcohol dependency has renewed interest in the pharmacological treatment of alcohol use disorders. When given under supervision, reviewers agree that supervised disulfiram helps reduce relapse in some people with alcohol problems (Heather, 1989, 1993; Brewer 1993; Hughes \& Cook, 1997). There has been no trial comparing its efficacy to acamprosate, but a pilot study has shown that it was twice as effective as naltrexone in reducing alcohol intake in patients with alcohol dependency who use cocaine (Carroll et al, 1993). The following data were obtained to compare the prescribing of disulfiram in various countries including Britain.

\section{The study}

Pharmaceutical sales are not generally disclosed. However, Dumex, the principal manufacturer of disulfiram, was asked to supply details for three consecutive years of tablet sales per 100000 of the adult population in 13 countries where their brand is the sole preparation available (except for the USA, where the figure includes all generic brands). Dumex divided the figures by a coeffcient to disguise actual sales while preserving relativities.

\section{Results}

Comparative sales in the 13 countries are shown in Table 1. Interpretation is complicated by the availability of several tablet sizes of disulfiram $(200 / 400 \mathrm{mg}$ or $250 / 500 \mathrm{mg})$ in most countries. Only $200 \mathrm{mg}$ tablets are available in Britain. Comparing the number of tablets sold in each 